\title{
REPRESENTAÇÕES DA TECNOLOGIA EM ALGUNS POEMAS DA LITERATURA BRASILEIRA
}

\author{
Angela Maria Rubel Fanini \\ Professora dos Cursos de Letras e de Comunicação da UTFPR
}

\section{RESUMO}

Neste artigo analisa-se como ocorre a representação literária do universo da tecnologia e do trabalho em alguns poemas de Castro Alves, Mário de Andrade e Oswald de Andrade. As visões formalizam-se, apresentando a tecnologia como destacada e exótica em relação ao meio econômico-social brasileiro, vislumbrado em seus aspectos arcaicos e residuais, causando espanto e surpresa na população; atrelada ao universo de poucos com elemento de entretenimento da elite; associada ao universo da produção, expropriando o trabalhador e, ainda, como artefato de importação, pouco orgânico, sujeito aos caminhos e descaminhos tomados pelas economias centrais liberais, enfrentando dificuldades de agregação real ao meio e à produção local.

\section{PALAVRAS-CHAVE}

Tecnologia; Trabalho; Representação literária; Poesia Brasileira.

\section{TECHNOLOGY REPRESENTATION IN SOME BRAZILIAN POEMS}

\begin{abstract}
This article analyses how the universe of technology and labour are depicted in literary terms in some Brazilian poems from the writers Castro Alves, Mario de Andrade and Oswald de Andrade. The poets portray this universe in the following approaches: modern technology dissociated from the Brazilian context painted as traditional and archaic; associated to industrial production and to workers' exploitation; linked to high class entertainment and as an imported good subjected to central capitalistic economies, facing difficulties to be aggregated to local production.
\end{abstract}

\section{KEYWORDS}

Technology; labour; literary representation; Brazilian Poetry. 


\section{TECNOLOGIA, TRABALHO E CULTURA}

Este artigo visa averiguar sob que perspectivas ocorre a representação do universo da tecnologia em alguns poemas da Literatura Brasileira. A análise se vincula à Linha de Pesquisa Tecnologia, Trabalho e Cultura que visa estudar a formalização do universo do trabalho e da tecnologia em produtos culturais, investigando como os intelectuais interpretam esses universos. A análise respalda-se em uma perspectiva materialista, procurando visualizar as articulações orgânicas, dialéticas e contraditórias entre as idéias e a realidade. O externo se torna interno à produção literária, sofrendo processos de "redução estrutural", de síntese e de transfiguração (Candido, 1985, p. 4)1 por intermédio de mediações ideológicas, culturais e históricas. O real passa a ser pensado e, no processo de formulação no universo das idéias, constitui-se enquanto pensado concreto. Cada intelectual apresenta uma constituição ímpar dessas articulações. Pretende-se analisar como essas interações se tornam visíveis no terreno das idéias e da poesia.

O foco na representação do trabalho e da tecnologia se ampara em teóricos (Marx (1986), Engels (1990), Lukács (1980), Antunes (2002)) que advogam a centralidade do trabalho na constituição ontológica do homem. Para esses autores, o ser humano é um ser social não somente porque vive em sociedade, mas porque inexiste fora dela e é a partir, sobretudo das relações de trabalho, que os homens vão se constituindo a si mesmos e aos outros em um processo ininterrupto marcado por escolhas subjetivas e condições objetivas. Seguindo o pensameto de Engels (1990), temse que:

Toda riqueza provém do trabalho, asseguram os economistas. E assim o é na realidade: a natureza proporciona os materiais que o trabalho transforma em riqueza. Mas o trabalho é muito mais do que isso: é o fundamneto da vida humana. Podemos até afirmar que, sob determinado aspecto, o trabalho criou o próprio homem. (p. 19)

Vinculando-se a essa visão, segue-se também que não há dissociação entre trabalho e tecnologia à medida que os artefatos e serviços tecnológicos criados pelo homem são originários de sua capacidade de trabalho no anseio de produzir, reproduzir,

\footnotetext{
${ }^{1} \mathrm{O}$ sociólogo brasileiro, ancorado em Lukács e Goldman, expõe seu ponto de vista sobre as relações orgânicas entre Literatura e realidade a partir de uma abordagem estrutural-sociológica em que a forma literária apreende a forma social em um movimento dinâmico de autonomia e interação. É nessa perspectiva que este artigo celebra a ligação entre as palavras se as coisas, ora em um movimento de reflexão, ora de refração.
} 
manipular, ordenar e alterar o ambiente social e natural. Sabe-se que há inúmeros ângulos a partir dos quais se pode apreender a tecnologia ${ }^{2}$. Há perspectivas transhistóricas em que se advoga a independência científica e técnica da evolução tecnológica às quais o homem e as sociedades apenas se submetem. As descobertas científicas e tecnológicas são inerentes ao sistema produtivo em eterna transformação, indeterminados por fatores políticos, ideológicos ou culturais. Aqui a tecnologia não é boa nem má, mas é neutra e funcional. O seu uso é que leva a benefícos ou malefícios sociais. Pode-se revolucionar a sociedade politicamente e continuar empregando o mesmo sistema tecnológico de produção de bens, entretenimento e cultura. Há visões substancialistas e deterministas em que predomina um entendimento de que a tecnologia constitui o ser humano independente de sua volição. A tecnologia é um sistema social e cultural da modernidade e nos forma e enforma, assim como ocorria nas sociedades teocráticas em que o homem se forjava a partir de um prisma religioso e místico. A sociedade moderna é tecnocrática e essa estrutura molda o pensamento, a consciência e o ser humano. A história da tecnologia na era moderna constitui o sujeito moderno, ou seja, um sujeito tecnológico. Nessa visão predomina, não raras vezes, um mal estar em relação à tecnologia que parece dominar e submeter a todos a uma unidimensionalidade, a uma razão instrumental. A perspectiva histórico-crítica contrapõe-se a esse conjunto, entendendo a tecnologia como uma práxis social, resultado de escolhas a partir do universo econômico, cultural e histórico. Em sendo uma construção humana, pode ser alterada, modificada, suprimida e reorientada. O homem em sociedade constitui a tecnologia e é por ela constituído em um processo de ininterrupto vir a ser em que as contradições de classe, de cultura, de etnia e de histórias específicas estão presentes e são estruturantes. Nessa linha, deve-se entender a tecnologia em seu eterno devenir a partir da perspectiva de um sujeito também em transformação. Essa postura distancia-se de uma "fetichização" da tecnologia, parafraseando a crítica de Marx à mercadoria e à falsa idéia de que seu valor é algo inerente e não externo. Verificar, no terreno empírico da produção poética, como certos poetas brasileiros vislumbram a relação homem, trabalho e tecnologia e, como formalizam literariamente essa relação, é o foco deste artigo. A análise se justifica uma vez que há raríssimos trabalhos acadêmicos que se debruçam sobre a representatividade literária nesse âmbito, o da tecnologia, em que em outras áreas já se encontra farta e avançada pesquisa.

\footnotetext{
${ }^{2}$ As considerações que seguem sobre as várias perspectivas de apreensão da tecnologia são uma interpretação feita pela autora das idéias contidas em FEENBERG, 1999.
} 
O estudo visa demonstrar que o universo do trabalho e da tecnologia podem ser pesquisados no discurso literário uma vez que este é vinculado à sociedade e pode ser importante fonte de conhecimento para o leitor, para o aluno e para o docente sobre a realidade circundante. Os literatos são homens de "seu tempo e país" e apresentam visões críticas, conformistas, reformistas e progressistas. O mundo do trabalho e da tecnologia tem sido alvo de importantes debates nas mais variadas áreas de conhecimento (Economia, Sociologia, Filosofia, Administração, História e Educação) e precisa também ser discutido nos estudos literários visto que a Literatura Brasileira é ensinada e lida nas escolas de Ensino Médio e nos cursos de formação de professores. Um olhar crítico que articule literatura e sociedade, especificamente no campo da produção simbólica sobre a produção material da existência, faz-se necessário para que se evitem os estudos a-históricos e estritamente formalistas da Literatua Brasileira A pesquisa procura articular as áreas de Literatura, História e Educação, demonstrando que a linguagem literária deve ser lida em sala de aula a partir de seus determinantes históricos, culturais e econômicos. Analisar como o intelectual do trabalho imaterial representa o trabalho material e a tecnologia contribui para que o docente e o discente visualizem esses universos reais a partir de vários e diversos olhares, propiciando uma visão crítica em que tanto o trabalho quanto a tecnologia sejam entendidos a partir das mediações de classe, de etnia, de cultura e de momento histórico.

A escolha dos poemas considerou somente aqueles em que o universo do trabalho e da tecnologia são formalizados, investigando-se esse universo por intermédio dos teóricos do trabalho e da tecnologia referidos. Nesse nível epistemológico privilegiou-se o marco marxista, enfocando as contradições. Procurou-se analisar a linguagem poética a partir tanto da filosofia da linguagem bakthiniana (1986) de orientação materialista em que a linguagem reflete o real e também o reftrata quanto da perspectiva sociológico-estrutural de Antonio Candido para quem os fatores externos se tornam internos mediante a forma literária em que uma análise composicional é importante, desde que atrelada à formação social da qual parte. Partiu-se do concreto, ou seja, dos poemas, construindo-a a reflexão sobre esses mediante um diálogo entre o discurso literário e o chão histórico brasileiro, mediado tanto pelas especificidades de cada poeta quanto pelas semelhanças entre eles. 


\section{CASTRO ALVES, MÁRIO DE ANDRADE E OSWALD DE ANDRADE: ALGUNS POEMAS EM TORNO DA TECNOLOGIA E DO TRABALHO}

No século XIX, o Brasil desponta como nação independente da metróple portuguesa e a recém nação passa a criar caminhos para se enquadrar na modernidade no campo das idéias e da produção capitalista, representada pelos países centrais da Europa, mais especificamente França e Inglaterra. No Segundo Império, o país se constitui como agroexportador, tendo por base econômica, majoritariamente, a produção de café e a mão-de-obra escrava. Apesar da economia escravista que vai de encontro ao ideário burguês progressista liberal, o país se moderniza tecnologicamente, implantando comunicação por telégrafo, faculdades, institutos de pesquisa e construindo estradas de ferro, portos, estaleiros ${ }^{3}$. Tem-se, portanto, uma nação de economia escravista, de idéias liberais-burguesas ora filtradas ${ }^{4}$, ora fora do lugar, e integrado, mediante a produção de monuculturas, ao capitalismo central, revelando fortes contradições sociais, políticas, econômicas e culturais. A Literatura Brasileira se debruça sobre esse social e plasma-se como "empenhada e interessada" ${ }^{5}$ em dizer e pintar essa realidade. Cada escritor, a partir de sua visão de mundo específica, recria esse universo que surge sob diferentes prismas. A relação entre as palavras e as coisas não é neutra ou de simples espelhamento, mas aí residem as tensões de uma articulação dinâmica e conflituosa.

$\mathrm{Na}$ poesia de Castro Alves ${ }^{6}$ (1847-1871), por exemplo, encontra-se uma formulação triunfalista do universo da tecnologia que adentrava o país, vislumbrando-se uma postura otimista em relação ao progressso técnico da nação. No poema "O Livro e a América", o poeta narra os grandes feitos das civilizações antigas. Destaca a criação da imprensa por Guttenberg como um ápice tecnológico na história do homem. Em uma postura ufanista e idealista, enfatiza que a América está predestinada a ser a pátria do livro e, em consequência, das idéias. A América contém o Brasil e este também, metonimicamente, acolhe o universo do livro. A partir daí, prevê-se que novas e

\footnotetext{
${ }^{3}$ A esse respeito, o Filme Mauá: o imperador e o rei, esclarece parte dessa história conturbada e contraditória entre as inovações tecnológicas, as idéias liberais, a maçonaria, o universo do favor, a economia da monocultura do café e o escravismo.

${ }^{4}$ Consultar a polêmica entre Schwarz (2000) e Bosi (1992) sobre a relação conflituosa das idéias importadas e sua adaptação, "filtragem" ou inadequação local devido a que o contexto econômicocultural do Brasil se diferencia do europeu de onde vem majoritariamente o universo das idéias.

${ }^{5}$ Consultar Candido, 1981, para quem a Literatura Brasileira é orientada por um desejo de documentar o local, sendo "empenhada e interessada" em pintar a sociedade brasileira no afã de civilizá-la e instituí-la pelas letras.

${ }^{6}$ Tomou-se a obra de Castro Alves, Editora Ediouro, s/data. Todas as citações correspondem a essa edição.
} 
revolucionárias idéias vão adentrar o país, possibilitando uma transformação social da nação, provavelmente em termos de ideário progressista-conservador burguês. Aí constrói-se uma visão da tecnologia aliada à transformação social em uma perspectiva idealista em que é pelo terreno unicamente das idéias que se modifica a sociedade: "Vós, que o templo das idéias \Largo - abris às multidões, $\backslash$ P'ra o batismo luminoso \Das grandes revoluções.”(p.17)

Na sequência desses versos, o poeta apresenta uma outra inovação tecnológica. No campo dos transportes, sabe-se que as ferrovias nacionais no século XIX, constituiram-se a partir de inversões de capital inglês e eram índices de modernidade tecnológica. No poema, o trem é formalizado de modo idealizado, vinculando-se não ao universo da produção material, mas da cultural, sendo que é o veículo que levará os livros ao povo inculto, à "multidão": "Agora que o tem de ferro $\backslash$ Acorda o tigre no cerro\e espanta os caboclos nus, \ fazei desse "rei dos ventos" pensamentos, \- Arauto da grande luz!...”(p.17) Aí, ocorre uma visão dicotômica entre a civilização e a natureza em que essa é "acordada", "surpeendida" pela inovação tecnológica. Animais e nativos estão no mesmo plano, indiferenciados, sendo ambos impactados pela tecnologia em um processo de alienação e estranhamento. O trem, carregando os livros e as idéias, passa pelos animais e pelos caboclos que chocados permanecem pasmos e "bestializados"? . Não se informa concretamente como esse produto tecnológico, tão poderosamente pintado como arauto da cultura e da alteração social, poderá transformar a vida dos caboclos. Apenas se cogita idealisticamente essa hipótese. Esses estão nus em uma alusão à ausência de cultura ilustrada e, certamente, não apreendem a nova tecnologia que está fora de seu universo, mas que poderá modificá-lo. Vê-se uma representação triunfalista e contraditória da tecnologia que é cantada como transformadora, mas simultaneamente, passa em velocidade, deixando para trás e intacta a cultura autóctone. A máquina aparece triunfante, surpreendendo, espetacularizada, como sinal do progresso técnico, mas fechada em si e alheia ao local, ao nativo e à natureza, constituindo-se como transcultural e trans-histórica em relação às condições em que se encontra o país naquele momento.

No contexto histórico da primeira República, na produção literária brasileira, em virtude obviamente das alterações sociais, econômicas e técnicas da sociedade

\footnotetext{
${ }^{7}$ O termo é emprestado do historiador Carvalho (1987) que retoma o vocábulo da citação de Aristides Lobo que à época da Proclamação da República do Brasil teria dito que o "povo a tudo asssitira bestializado", ou seja, sem tomar parte e surpreso com o advento da nova ordem.
} 
brasileira, ocorrem muito mais aparições do progresso técnico sob diversas perspectivas ideológicas e formais. O Brasil da República Velha, embora ainda vinculado à monocultura cafeeira, já apresenta outras tantas inovações tecnológicas como o telefone, o cinema, as rodovias asfaltadas, o elevador, o automóvel, o rádio. Esse universo tecnológico não passa despercebido pelos poetas, romancistas e dramaturgos que o representam de vários ângulos. A obra poética de Mário de Andrade $^{8}$ (1893-1945) é um dos exemplos dessas migrações dos fatores externos para a fatura poética. No poema "O Domador", nota-se que, embora haja diferenças substantivas entre a poética de Mario de Andrade e de Castro Alves, há uma certa confluência no tocante à dicotomia entre progresso técnico e filhos da terra. Nesse poema, o escritor vai enumerando as conquistas técnicas e civilizatórias da cidade de São Paulo e coloca-as, lado a lado, com a permanência da tradição, do antigo, do histórico-pretérito. Surgem o bonde e o asfalto juntamente com os "Filets de manuelino". Entretanto, o que se enfatiza, ao final do poema, é a dicotomia entre o país dos imigrantes, sobretudo italianos e alemães, associado ao progresso técnico na figura do automóvel que contrasta com o natural da terra, filho de bandeirantes que olha com admiração e surpresa a inovação tecnológica que a ele também aparenta alheia: "Aos aplausos do esfusiante clown, $\backslash$ heroico sucessor da raça heril dos bandeirantes, I passa galhardo um filho de imigrante, loiramente domando um automóvel!” (p.41). A tecnologia aqui é vinculada ao imigrante que traz a novidade e dá o espetáculo ao natural da terra, remontando-se, parece, à relação do índio com o português, descrita já de início na Carta de Pero Vaz de Caminha, formalizando uma visão ingênua, simplista e reduzida do autóctone em relação ao civilizado e seus artefatos tecnológicos. A tecnologia não é associada ao trabalho ou transformação social e sim ao entretenimento de poucos. Aí se processa uma visão minimamente crítica em relação aos privilégios oriundos de classe social, mas que é minimizada pela fraqueza do nativo frente ao outro "civilizado" e pela heroicização do emigrante.

Em outro poema, "Noturno de Belo Horizonte", descreve-se e narra-se a trajetória do trem que passa por Minas Gerais e vai revelando as contradições sociais, econômicas e culturais de um Estado a que o poeta chama, ironica e criticamente, de "fruta paulista" em virtude de sua dependência de São Paulo, Estado mais poderoso política e ecomicamente na época da República Velha. O trem representa a tecnologia

\footnotetext{
${ }^{8}$ Tomou-se a obra de Mario de Andrade, 1980. Todas as citações correspondem a essa edição.
} 
que deixa ver as mazelas sociais e políticas a partir de sua intromissão nesse cenário. $\mathrm{O}$ trem leva o leitor a uma viagem em que se deslindam os acertos e desacertos de Minas Gerais onde o arcaico, o residual, o atraso se revelam em contraste com a ferrovia e o trem em alta velocidade. Entretanto essa tecnologia entra em dissonância com o meio e apresenta problemas: “Apesar da perfeição das estradas-de-ferro $\$ E da inflexível providencia dos horários, $\backslash$ Encontros descarrilamentos mortes...(p. 128). Por outro lado, o trem também leva algo positivo ao cenário nacional, como em Castro Alves. A tecnologia vai fecundar o deserto, tendo-se uma visão dicotômica entre cultura civilizada e incultura do meio. Em Minas Gerais, parece não haver cultura, mas o trem pode levá-la: "Minas progride! \Mãos esqueléticas de máquinas britando minérios, $\backslash$ As estradas de ferro estradas de rodagem $\backslash$ Serpenteam tesoficamente fecundando $o$ deserto.”(p.131). Apesar dessa idéia de progresso positiva, há também aí uma crítica ao mundo do trabalho à medida que a tecnologia introduzida na produção por intermédio da máquina não alivia a labuta do trabalhador visto que o vocábulo "esqueléticas" informa a expropriação do operário. A mão humana faz parte da máquina, é seu desdobramento, denotando-se a exploração e desumanização do trabalhador.

Em outro poema, "Danças", o poeta, a partir de perspectiva jocosa, associa o movimento de subida e descida do elevador à economia agroexportadora do açúcar e do café com suas quedas e altas no mercado externo. A tecnologia aqui se vincula a um chão histórico econômico instável: "O elevador subiu aos céus, ao nono andar, $\backslash \mathrm{O}$ elevador desce ao subsolo, $\mid$ Termometro das ambições. $\backslash \mathrm{O}$ açúcar sobe. $\backslash \mathrm{O}$ café sobe.(...)\} Quebras formidáveis! \Riquezas fetos de cinco meses \Já velhas como Matusalém" (p.159). O progresso técnico não está solidamente associado e articulado ao capital produtivo, comparecendo de modo frágil, denotando sua origem importada dentro de uma economia local não industrializada.

A poesia de Mário de Andrade é sobejamente conhecida por cantar a cidade de São Paulo e aí, em inúmeras vezes, há um deslumbramento com o progresso técnico, incluindo vários artefatos tecnológicos. Em "Louvação Matinal", tem-se uma formalização da tecnologia associada ao movimento, ao vir a ser, ao novo, ao despertar da cidade haja vista o próprio título que aponta para a aurora, o início, o começo de tudo. Em um dos trechos, tem-se:

Nombrada da terra em força nova da manhã! Ao pé de mim São Paulo em rosa vibra cheirando vida! (...) Rangem os caminhões. Padeiro entrega o pão. O leite 
Ferve no fogo. A feira grita de Cor. As notícias

Correm povo no galopão folgado dos jornais.

Autoónibus bufando. Tudo bufando, abrindo asa...

A cidade mexe de vida fresca, temporã. (p.195)

Aqui a tecnologia e o homem se indiferenciam, pois todos se reduzem a "bufar" em um mesmo movimento de progressso, de devenir dado a partir de uma visão triunfalista e positiva da cidade paulista.

Já em outro poema, "O poeta come Amendoim (a Carlos Drummond de Andrade)", o escritor apresenta uma visão parcialmente contrária ao progresso, apegando-se ao passado Imperial, contrapondo-o ao tempo em que vive, ou seja, o da República. Essa perspectiva contrastante com a de glorificação do progresso e da civilização, contribui para construir um conjunto discursivo poético mais complexo visto que visões díspares se formalizam, comprovando-se que o externo em que há múltiplas vozes migra para o interior da linguagem literária que também se diversifica em um caleidoscópio de idéias diversas:

A noite era pra descansar. As gargalhadas brancas dos mulatos...

Silêncio! O Imperador media os seus versinhos. (...)

Porém, o desastre verdadeiro foi embonecar esta república temporã.

A gente inda não sabia se governar...

Progredir, progredimos um tiquinho

que o progresso também é uma fatalidade...Será o que o Nossso Senhor quiser!...(p-109)

Aqui, inclusive, emerge o país ainda muito apegado ao Catolicismo em que o destino do progresso que é, em essência mundano e secular, dá-se pela via espriritual, contrariando a modernidade que fica "fora do lugar" na "República temporã". Essa posição dual entre o passado e o presente mais "moderno e tecnológico" reflete as próprias condições econômico-sociais do Brasil à época visto que se constitui entre o agrário e o urbano, a democracia e o coronelismo, o liberalismo e o favor, a economia majoritariamente de exportação de produto primário e a incipiente economia e indústria interna.

Dentro ainda desse cenário histórico e literário em contradição, encontramos também certas representações da tecnologia na poesia de Oswald de Andrade9 (18901954). Em "falação" (poema-programa que é uma redução do "manifesto da poesia pau-

\footnotetext{
${ }^{9}$ Tomou-se a obra de Oswald de Andrade, 1978. Todas as citações correspondem a essa edição.
} 
Brasil), há três versos muito indicativos da visão de progresso técnico que reaparece constantemente na obra do poeta e que também ocorre em outros discusros históricos, sociológicos e políticos sobre o Brasil da época. A perspectiva de uma modernidade frágil, de exportação, não vinculada à cultura e ao capital produtivo local é uma constante na representação da nação, não só na literatura, mas também em outros produtos culturais brasileiros. A visão de que o contexto local distorce, torce, altera, modifica a cultura importada está em variados discursos que definem o Brasil como uma nação que fica entre o arcaico e o moderno, não conseguindo se definir dentro de uma ordem burguesa liberal. Essa indefinição que a todo momento solapa a identidade moderna do Brasil acaba por fornecer uma caracterização móvel, fluida, incerta e refratária ao progresso para a sociedade brasileira, como os versos a seguir atestam: "Uma sugestão de Blaise Cendras:- Tendes as locomotivas cheias, ides partir. Um negro gira a manivela do desvio rotativo em que estais. $\mathrm{O}$ menor descuido vos fará partir na direção oposta ao vosso destino". (p. 77). Essa tecnologia, por ser um produto pouco orgânico da economia brasileira, aflora como exótica, sendo cantada, muitas vezes, pelos poetas como algo destacado da paisagem, estranho, alheio aos nativos, aos brasileiros, sobretudo àqueles que estão na base da produção e não se beneficiam dessa tecnologia, ou dela não participam enquanto agentes, como os demais grupos que comandam o Brasil econômica e politicamente.

Ainda no mesmo poema, a dissonância do país tradicional e o do país industrializado ocorre em imagem que alia índices do catolicismo e do progresso técnico no mundo do trabalho. Nos versos a seguir, tem-se "As procissões saíram do bojo das fábricas" (p.77). Aqui, a dessacralização do mundo empreendida pelo capital, pela indústria e pela ciência e tecnologia que amparam a produção industrial, encontra obstáculos em uma sociedade ainda associada ao espírito do catolicismo avesso a uma visão secular e materialista. A linguagem aproxima os termos "procissão" e "fábricas", demonstrando que essa aparente modernidade, é a todo momento penetrada por outra ordem ideológica que a enfraquece ou a altera, pois a coloca "fora do lugar".

A industrialização e o mundo do trabalho comparecem no poema "metalúrgica" em que se descreve e se formaliza um universo a um só tempo inóspito e produtivo. O poema se faz com dez versos em que o operariado é representado apenas no penúltimo verso, despersonalizado e produzindo apenas o trabalho material haja vista que o trabalho pensante é associado à tecnologia e à maquinaria que aparecem no segundo verso, caracterizadas como produtora do trabalho intelectual. O poema se 
constrói com o foco na produção, tratando de números, de quantias, agregando uma linguagem econômica. Entretanto, esses números se tornam irreais à medida em que no primeiro verso, o poeta informa uma quantidade de calor insuportável à sobrevivência do operariado como forma de crítica social a partir do uso de imagem hiperbólica:

\author{
$1300^{\circ}$ à sombra dos telheiros retos \\ 12000 cavalos invisíveis pensando \\ 40000 toneladas de níquel amarelo \\ Para sair do nível das águas esponjosas \\ E uma estrada de ferro nascendo do solo \\ Os fornos entroncados \\ Dão o gusa e a escória \\ A refinação planta barras \\ E lá embaixo os operários \\ Forjam as primeiras lascas de aço. (p.102)
}

O objeto do poema é a descrição de uma metalúrgica, entretanto surge no cenário o sujeito humano na figura do trabalhador que sofre o processo tecnológico tanto do ponto de vista da estafa física, submetido a condições materiais subumanas do local de trabalho quanto de seu assujeitamento à máquina visto que é a tecnologia que "pensa" e não o operário. Aqui a tecnologia e a produção se impõem ao operário que se vê desumanizado e enfraquecido. A sua posição de subalteno está formalizada tanto na linguagem que o descaracteriza como ser pensante quanto em sua localização e aparição apenas no penúltimo verso.

\title{
CONSIDERAÇÕES FINAIS
}

A leitura dos poemas referidos, enfocando-se as representações do universo da tecnologia e do trabalho na sociedade brasileira de fins do século XIX até a implantação da República Velha, demonstra que os poetas estudados não foram insensíveis à visibilidade do progresso técnico de origem européia que aos poucos se fazia concretizar no país. A representação ocorre em menor monta em Castro Alves uma vez que sua obra se limita a um tempo histórico em que o país apenas adentrava nas modernidades tecnológicas advindas sobretudo da Inglaterra. A visão aí formalizada é bastante frágil e a tecnologia se destaca como algo exótico aos nativos. A figura do trem a partir da implantação das ferrovias com inversão inglesa merece destaque. Essa tecnologia não se conecta à produção e ao trabalho, permanecendo como um artefato que atravessa e se agiganta frente ao cenário, sem dele ser parte orgânica. Em Mário de 
Andrade, percebe-se ainda que o trem é motivo de representação literária, mas, parcialmente modificado. Aqui a tecnologia já está mais organicamente adaptada à paisagem. A partir dela, de seu progresso, de seu movimento vê-se um país arcaico em que a inércia se descobre em contraste com a rapidez com que ele passa pelas cidades interioranas. O progresso técnico é vislumbrado como positivo, mas não sem contradições, pois no cenário da máquina, do automóvel, do elevador, do asfalto irrompe a História Brasileira, cujo contexto econômico, social e cultural difere em muito dos países de onde vem a tecnologia. O poeta pinta essas contradições, desnudando o universo de expropriação do trabalhador, da economia agroexportadora frágil, dependente do valor imposto pelos mercados internacionais e do atraso cultural dos nativos, dos herdeiros dos Bandeirantes, em relação à nova configuração populacional com a vinda dos imigrantes italianos e alemães em especial. A tecnologia aqui serve mais para o entretenimento de poucos do que para a produção para muitos. Os avanços tecnológicos do século XX são visíveis, mas parecem muitas vezes "fora do lugar", emperrados por um Brasil residual, tradicional, vinculado ao século XIX. Há uma visão saudosista em que o Império se sobrepõe como um lugar utópico deslocado por uma República sem identidade. Oswald de Andrade apresenta também as dissonâncias entre a tecnologia importada e seu uso "filtrado", em outro "fuso horário e cultural" pelos brasileiros não pertencentes à elite. A crítica à expropriação do trabalhador pelas novas tecnologias e maquinarias também é veiculada, assumindo-se a existência de diferenças gritantes de classe social e a dominância da tecnologia sobre o homem. Entretanto, o universo da produção incrementada pela tecnologia comparece em uma visão também positiva.

A representação do universo tecnológico a partir de poemas da Literatura Brasileira comprova que os escritores não são alheios ao meio social, formalizando-o por intermédio de visões díspares sobre as possíveis articulações entre trabalho, tecnologia e sociedade. O externo se torna interno, demonstrando que o discurso literário pode nos fornecer um retrato do Brasil e de como o país incorpora ou não as tecnologias importadas e como essas determinam ou não a vida dos brasileiros. $\mathrm{O}$ estudo da representação simbólica do real via discurso literário pode conscientizar os leitores de que a literatura não é de orientação gratuita, de puro entretenimento, mas articulada às condições concretas da vida real de que parte. 


\section{REFERÊNCIAS}

ALVES, Rubem. Tecnologia e humanização. In: Revista Paz e Terra, n. 08.Rio de Janeiro: Ed. Civilização Brasileira, 1968.

ANDRADE, Oswald de. Poesias Reunidas. 5.ed. Rio de Janeiro: Civilização Brasileira, 1978.

ANDRADE, Mario. Poesias completas. São Paulo: Livraria Martins Editora, 1980.

ANTUNES, Ricardo. Os sentidos do trabalho: ensaio sobre a afirmação e a negação do trabalho. 6.ed. São Paulo: Boitempo, 2002.

ALVES, CASTRO. Poesias completas de Castro Alves. Rio de Janeiro: Ediouro, s/d.

BAKHTIN, Mikhail. Marxismo e Filosofia da linguagem. Trad. Michel Lahud e Yara Frateschi Vieira. São Paulo: Hucitec, 1986.

BOSI, Alfredo. A escravidão entre dois liberalismos. In: Dialética da colonização. São Paulo: Companhia da Letras, 1992.

CANDIDO, Antonio. Formação da Literatura Brasileira (Movimentos decisivos). 6. ed. v.2. Belo Horizonte: Ed. Itatiaia, 1981.

Literatura e sociedade: estudos de teoria e história literária. 7. ed. São Paulo: Ed. Nacional, 1985.

CARVALHO, Jose Murilo. Os bestializados: o Rio de Janeiro e a República que não foi. São Paulo: Companhia das Letras, 1987.

ENGELS, Friedrich. O papel do trabalho na transformação do macaco em homem. 4. ed. Rio de Janeiro: Global, 1990.

FEENBERG, A. A filosofia da tecnologia numa encruzilhada. Tradução de Newton Ramos de Oliveira. http://www-rohan.sdsu.edu/faculty/feenberg/1999.

KARL, Marx; A Maquinaria e a Indústria Moderna. In: O capital: crítica da economia política. Trad. Reginaldo Santanna. 12 ed. Trad. Reginaldo Santanna. Rio de Janeiro: Bertand, 1988.

LUKÁCS, Georg. The ontology of social being: Labour. Londres: Merlin Press, 1980.

IGLÉSIAS, Francisco. Trajetória política do Brasil (1500-1964). 3. ed. São Paulo: Companhia das Letras, 1993. 
MAUÁ: O IMPERADOR E O REI. Direção de Sérgio Rezende. Rio de Janeiro/Inglaterra. Produção Lagoa Cultural e Esportiva. Distribuição Buena Vista, 2000.

SCHWARZ, Roberto. As idéias fora do lugar. In: Ao vencedor as batatas: forma literária e processo social nos inícios do romance brasileiro. 34. ed. São Paulo: Duas Cidades, 2000. 